\title{
Research on group enterprise multimedia information publishing system
}

\author{
Dong Zhimin \\ Hengshui power supply branch, Hebei province, State grid, China
}

\begin{abstract}
A electric power group enterprises to actively explore the innovation of enterprise culture management, making full use of modern information and communication technologies, construction of trans-regional multimedia information publishing platform. Construction of a municipal pilot units in Group region, for example, through consolidation, Office LANs, corporate networks in electric power communication network, cable TV network, realized with pictures, video, PPT, FLASH animations, WORD documents, WEB pages, video conference streams, radio, television, and other media as the carrier's digital communications.
\end{abstract}

\section{Introduction}

A large-scale electric power group company for the process of integration of enterprise culture construction, make full use of information and communications data network construction, build internal trans-regional enterprises multimedia information publishing platform, linking the Group Headquarters and city and County grades[1]. Currently, group a city level pilot units regional construction has completed, in suburban and transforming centralized control station deployed a total of 23 multimedia network TV and terminal multimedia broadcasting machine, has achieved enterprise internal group, and layered, and points regional clock work life, and Humanities thought, and education training, various propaganda, has created knowledge shared, and learning exchange, and image show, and information interactive of platform, the platform support pictures, and video, and PPT, and FLASH animation, and WORD document, and WEB page, and video conference flow, and Radio, television and other media, has achieved notice, training, news, technical reports, poetry, on demand, brand planning, cultural salons, professional educational organization, production planning, field work, fact sheets and other information shown.

\section{Multimedia information publishing system architecture}

Multimedia information publishing system architecture is composed of hardware and software system architecture below introduces basic features of hardware infrastructure and software systems.

\subsection{Hardware infrastructure}

The system used $\mathrm{B} / \mathrm{S}$ architecture, by terminal office computer, and room server, and information communications network, and broadcast controlled machine, and displayed equipment composition, information released by server concentrated management control, Terminal Office personnel through browser landing server management software, making various program, via Group internal network transmission to each displayed end broadcast controlled machine, broadcast controlled machine through VGA line, and audio line, and HDMI HD digital line released to each displayed equipment[2-3]. As shown in Figure. 1.

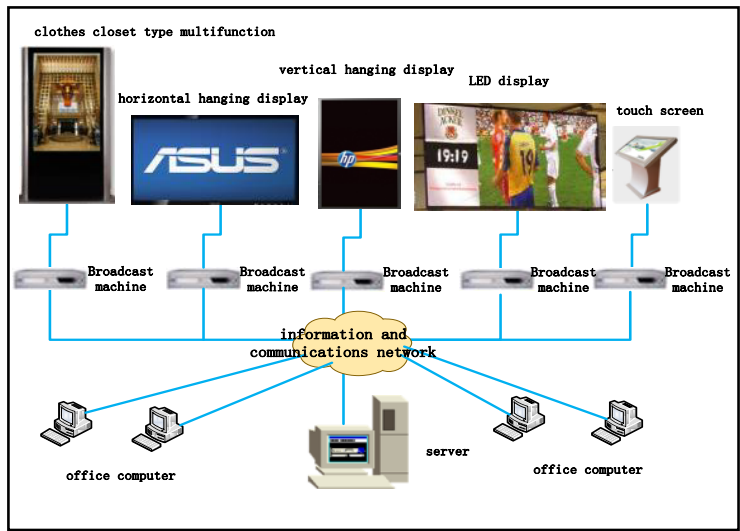

Figure 1. A hardware system architecture diagram.

Server using DELL2850,2G memory 300G-RAID1 hard drive, dual supply. Grew the business to increase in the future, will replace minicomputers.

Terminal published computer: Lenovo's widescreen desktop computers, monitor aspect ratio 16:9, core 2 Duo dual-core $3.2 \mathrm{GHz}, \mathrm{RAM} 2 \mathrm{G} / \mathrm{HD} 500 \mathrm{G}$, adapter boards support the TCP/IPv4 protocol.

Broadcast machine for ultra-thin embedded computers and embedded display devices such as televisions or placed in the top of the ceiling at the back. Via VGA cable, audio cable, HDMI high definition digital cable 
connections, such as LCD or plasma TV, professional landscape, portrait displays, touch screens, LED screens, stitching large-screen display devices, through the VGAAV module is connected directly to your computer host and monitor[4-5]. NIC board support the TCP/IPv4 protocol, parameter configuration: CPU $1.6 \mathrm{GHz}$, memory, $1 \mathrm{G}$, hard $80 \mathrm{G}$.

Display device: $5 \mathrm{mx} 0.5 \mathrm{~m}$ plasma TV screen ; $4 \mathrm{mx} 4 \mathrm{~m}$ stitching large screen; 32 inch LED thin LCD TV;55 inch LED thin LCD TV.

Information and communication networks: the group domain information in a city traffic network as in Figure 2 , is divided into a core layer, convergence layer and access layer, core router with Huawei NE40E-X8, aggregation layer router Huawei NE20E-X8, access layer using Huawei S9303 switch line using $1 \mathrm{G}$ fibre connection, access network using the OSPF protocol, bringing together core network using the BGP protocol to transmit data. The VPN dedicated communication network through the establishment of information channels transmitting multimedia information publishing data to ensure transmission reliability and bandwidth and QOS quality.

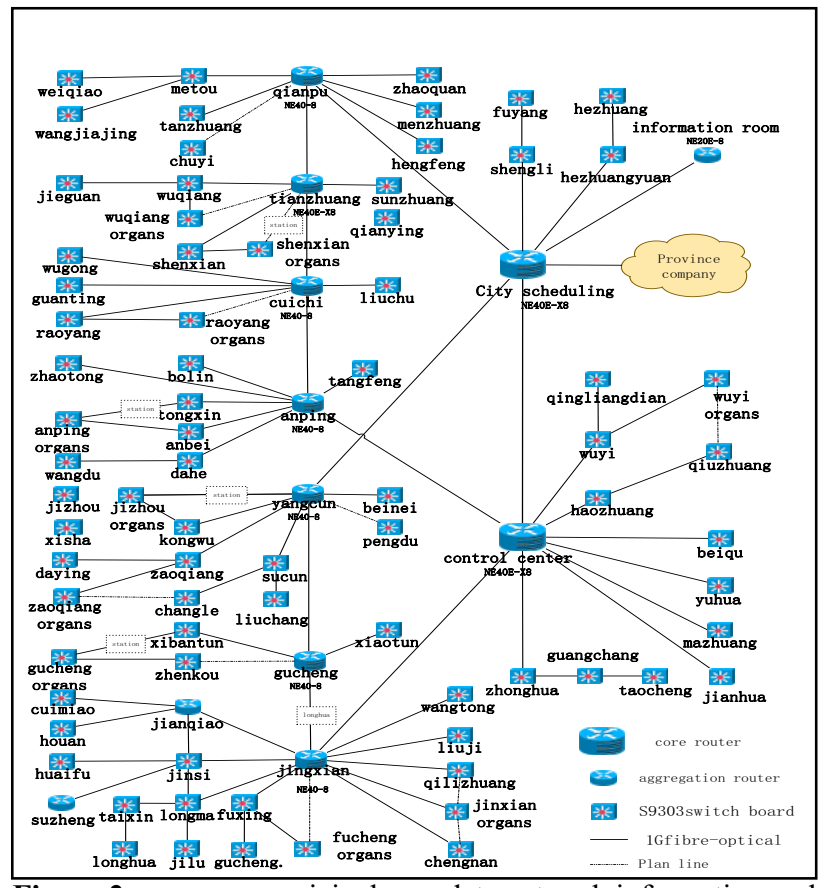

Figure 2. group a municipal area data network information and communication.

\subsection{Software systems basic functions}

Management end software: will was installation to multimedia information released system server, general user and the administrator are can through browser landing this software to upload pictures, and text, and PPT, and FLASH animation, and music, and video, various material file, making program scene, management program list, will latest of program released to play end; administrator also can group, and grading, and points domain set different user of permission, on various program for audit, and remote monitoring broadcast controlled machine state and log information, and set timing opened and closed[6].
Broadcast software: Studio Adone System broadcast software needs to be installed according to instructions downloaded from the management side of the server needed programming, called broadcast machine installed WORD, EXCEL, PPT format, FLASH Player plug-in, achieve a variety of dynamic transitions, page and scroll through results, and publish it via VGA or HDMI HD digital lines to the specified set.

\section{System construction and maintenance}

Group pilot municipal units of multimedia information issuing system construction in two phases, the first phase of construction of 9 points, the second phase construction of 14 points, a total of 23 points. As shown in Table 1 .

Table 1. Construction of the multimedia information publishing system

\begin{tabular}{|c|c|c|c|}
\hline locations & display & install style & $\underset{t}{\operatorname{coun}}$ \\
\hline building elevator hall & $\begin{array}{l}\text { 32inch } \\
\text { LED TV }\end{array}$ & $\begin{array}{c}\text { solid wall- } \\
\text { mounted }\end{array}$ & 2 \\
\hline $\begin{array}{l}\text { scheduling elevator } \\
\text { hall }\end{array}$ & $\begin{array}{l}\text { 32inch } \\
\text { LED TV }\end{array}$ & $\begin{array}{l}\text { solid wall- } \\
\text { mounted }\end{array}$ & 1 \\
\hline marketing office & $\begin{array}{l}\text { 55inch } \\
\text { LED TV }\end{array}$ & $\begin{array}{l}\text { solid wall- } \\
\text { mounted }\end{array}$ & 1 \\
\hline marketing office fees & $\begin{array}{l}55 \text { inch } \\
\text { LED TV }\end{array}$ & $\begin{array}{l}\text { solid wall- } \\
\text { mounted }\end{array}$ & 1 \\
\hline organs restaurant & $\begin{array}{l}\text { 55inch } \\
\text { LED TV }\end{array}$ & hang ceiling & 2 \\
\hline hezhuang restaurant & $\begin{array}{l}\text { 55inch } \\
\text { LED TV }\end{array}$ & $\begin{array}{l}\text { solid wall- } \\
\text { mounted }\end{array}$ & 1 \\
\hline $\begin{array}{l}\text { repairing east } \\
\text { building }\end{array}$ & $\begin{array}{l}55 \text { inch } \\
\text { LED TV }\end{array}$ & $\begin{array}{l}\text { decorative wall } \\
\text { embedding }\end{array}$ & 1 \\
\hline $\begin{array}{c}\text { line west building } \\
\text { east }\end{array}$ & $\begin{array}{l}55 \text { inch } \\
\text { LED TV }\end{array}$ & $\begin{array}{c}\text { decorative wall } \\
\text { embedding }\end{array}$ & 1 \\
\hline $\begin{array}{c}\text { line west building } \\
\text { west }\end{array}$ & $\begin{array}{l}55 \text { inch } \\
\text { LED TV }\end{array}$ & $\begin{array}{c}\text { solid wall- } \\
\text { mounted }\end{array}$ & 1 \\
\hline $\begin{array}{c}\text { operation second } \\
\text { building }\end{array}$ & $\begin{array}{l}32 \text { inch } \\
\text { LED TV }\end{array}$ & $\begin{array}{l}\text { solid wall- } \\
\text { mounted }\end{array}$ & 1 \\
\hline $\begin{array}{l}\text { logistics service } \\
\text { center }\end{array}$ & $\begin{array}{l}55 \text { inch } \\
\text { LED TV }\end{array}$ & $\begin{array}{l}\text { decorative wall } \\
\text { embedding }\end{array}$ & 1 \\
\hline $\begin{array}{c}\text { qianpu operations } \\
\text { center }\end{array}$ & $\begin{array}{l}55 \text { inch } \\
\text { LED TV }\end{array}$ & hang ceiling & 1 \\
\hline $\begin{array}{c}\text { yangcun operations } \\
\text { center }\end{array}$ & $\begin{array}{l}55 \text { inch } \\
\text { LED TV }\end{array}$ & $\begin{array}{c}\text { solid wall- } \\
\text { mounted }\end{array}$ & 1 \\
\hline $\begin{array}{c}\text { jingxian operations } \\
\text { center }\end{array}$ & $\begin{array}{l}55 \text { inch } \\
\text { LED TV }\end{array}$ & $\begin{array}{l}\text { solid wall- } \\
\text { mounted }\end{array}$ & 1 \\
\hline $\begin{array}{l}\text { anping operations } \\
\text { center }\end{array}$ & $\begin{array}{l}55 \text { inch } \\
\text { LED TV }\end{array}$ & hang ceiling & 1 \\
\hline $\begin{array}{c}\text { hengshui } \\
\text { operationscenter }\end{array}$ & $\begin{array}{l}55 \text { inch } \\
\text { LED TV }\end{array}$ & hang ceiling & 1 \\
\hline $\begin{array}{c}\text { building } \\
\text { management }\end{array}$ & $\begin{array}{l}55 \text { inch } \\
\text { LED TV }\end{array}$ & $\begin{array}{l}\text { solid wall- } \\
\text { mounted }\end{array}$ & 1 \\
\hline electric company & $\begin{array}{l}55 \text { inch } \\
\text { LED TV }\end{array}$ & $\begin{array}{l}\text { solid wall- } \\
\text { mounted }\end{array}$ & 1 \\
\hline industry company & $\begin{array}{l}32 \text { inch } \\
\text { LED TV }\end{array}$ & hang ceiling & 1 \\
\hline office loudaping & $\begin{array}{c}\text { plasma } \\
\text { TV }\end{array}$ & $\begin{array}{c}\text { solid wall- } \\
\text { mounted }\end{array}$ & 1 \\
\hline schedule loudaping & $\begin{array}{l}\text { plasma } \\
\text { TV }\end{array}$ & $\begin{array}{l}\text { solid wall- } \\
\text { mounted }\end{array}$ & 1 \\
\hline
\end{tabular}

After the multimedia information publishing system up and running, due to broadcast controlled machine long-term high load run in buildings ceiling, and 
substation shipped dimension Center Hall, and restaurant storage between, and hollow decorative wall, and stairs sandwich suite, and corridor wall body wall, dust more, work environment bad, unmanned unattended of industrial production field, easy appeared built-in fan blocking turned, led to thermal system failure, makes system automatically shut machine or overheating burned CPU and motherboard[7].

\section{Not ash radiator fan-free design principles}

The result has applications for invention patents, provides a dense ash cooling systems, including heating1, thermal devices2, chassis3, cooling structure, thermal2 conductivity equipment end connected to heating 1 and cooling structure, heating1 parts located inside the chassis 3 , heat sink structure outside the chassis 3 . Figure 3

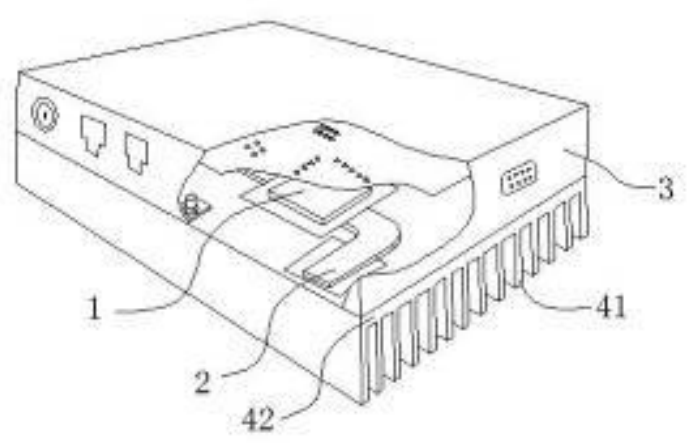

Figure 3. No ash cooling without fan schematic.

Thermal conductivity device can be copper, it can contain other convective type heat spreader. Copper strips, the best use of copper sheet with a higher thermal performance, and according to the device space to determine the dimensions bar. If used to control machines, bar dimensions length $\mathrm{x}$ width $\mathrm{x}$ thickness $=70 \mathrm{mmx} 50 \mathrm{~mm} \times 12 \mathrm{~mm}$. Meanwhile, after taking into account costs and cover both dust effects, thermal solution optional length $\mathrm{x}$ width $\mathrm{x}$ thickness $=220 \mathrm{~mm} \times 150 \mathrm{~mm} \times 30 \mathrm{~mm}$ special heat conducting aluminum heat sink profiles. In addition, the parts joints to choose higher technical parameters of silicon or silicone grease.

Heating and cooling structure in individual cases is in contact, because the heat sink structure actually played a role in conduction of heat, can be seen as a collection of thermal structure and thermal solution.

Further, the foregoing not fouling in cooling system, heat sink structure for the Panel41. Is actually in the original equipment or multilateral set heat sink, or a direct replacement for the original equipment rear cover plates, achieve the purpose of cooling.

Further, the foregoing not fouling in cooling system, heat sink with fins42 on the Board41. Fin42 extended the cooling area, better cooling effect can be achieved. In order to achieve a better cooling effect, where you can change the size and arrangement of fins42, and even changes the fin 42 array arranged acicular structure.

Further, the foregoing not fouling in cooling system, finned42 heating Panel41 centered on the axis of radial distribution. This form applies to fans in the central situation.

Further, the foregoing not fouling in cooling system, arranged parallel to the fins on the Panel. This form applies to fans in the central situation.

Further, the foregoing not fouling in cooling system, heat sink away from the side of the chassis with cooling fan. The cooling fan is external to the chassis, auxiliary heat sink structure for cooling. If the heat sink with fins on the Board, fan is located in the thermal center of the plate.

Further, the foregoing not fouling in cooling system, thermal structure and chassis side cover a whole set or fixed connections, or thermal structure and cover plate fixed on the side of the chassis structure, can replace the chassis side cover. For example, thermal structures and chassis cover the same shape, buckle and bolts position the same structure, you can replace the cover to the chassis

Meanwhile, heat sink structure outside the chassis, and heat sink structure can replace the cover on the side of the chassis, in order to minimize heat transfer path length, equipment boards front and thermal structure, site of CPU heat dissipation structure.

Further, the foregoing not fouling in cooling system, heat conduction and thermal solution structure is arranged between the semiconductor refrigeration piece. Semiconductor refrigeration piece actually played a role in enhance the effect of thermal conductivity, heat ends and the thermal conductivity of a semiconductor refrigeration device connected, radiating side connected to the thermal structure of semiconductor refrigeration, thermoelectric power on the device.

Further, the foregoing not ash cooling systems used for control or projector.

Provides of a not product gray of thermal system will thermal structure placed chassis zhiwai, chassis within no fan, chassis both inside and outside no too much of of air exchange, chassis within on not has dust gathered; and thermal structure Shang if has product gray also without on equipment for demolition, directly cleanup can, and convenient; while moved except chassis within of thermal fan, save has chassis within of space, conducive to equipment of miniaturization; and structure simple, can directly through on existing equipment modified achieved, applies range wide.

\section{Physical processing and production of cooling system for broadcast machine}

Renovation of the Studio machine to fanless cooling system in embedded computer systems (broadcasting) within a small space, effective and bridge CPU chip heat generated while working in the fanless cooling system under the conditions of export. Working under the 
temperature $75^{\circ} \mathrm{C}$ rise in temperature under conditions of balance. In accordance with the broadcasting machine lumen design of a thermal block, without damaging the structure of the broadcasting cases, using broadcast machine heat pipe fixtures, to thermal block fixing on the original duct position. Block's thermal dissipation space expanded, connected with an external heat sink, cooling area, in order to achieve the intended results.

Concrete step is to broadcast original dismantle the fan cooling system. Bridge pads and uniform piece of the silicon wafer coated with grease and the grease evenly to the surface of the CPU. Machined cooling block with 4 screws on the original location of the duct, screws tightened as much as possible to make blocks with a bridge with CPU surface in close contact. Aluminum processing for the fin structure, as an external heat sink, and it is fixed with 4 screws to the base pieces that have a good coating of silicone grease uniformly apically. Figure 4

Cooling block select red copper material with high heat dissipation. Dimensions length $\mathrm{x}$ width $\mathrm{x}$ thickness $=70 \times 50 \times 12 \mathrm{~mm}$. Taking into account the cost and effect of dust-proof cover, fins use length $\mathrm{x}$ width $\mathrm{x}$ thickness $=220 \times 150 \times 30 \mathrm{~mm}$ good thermal conductivity of aluminum heat sink extrusions[8].

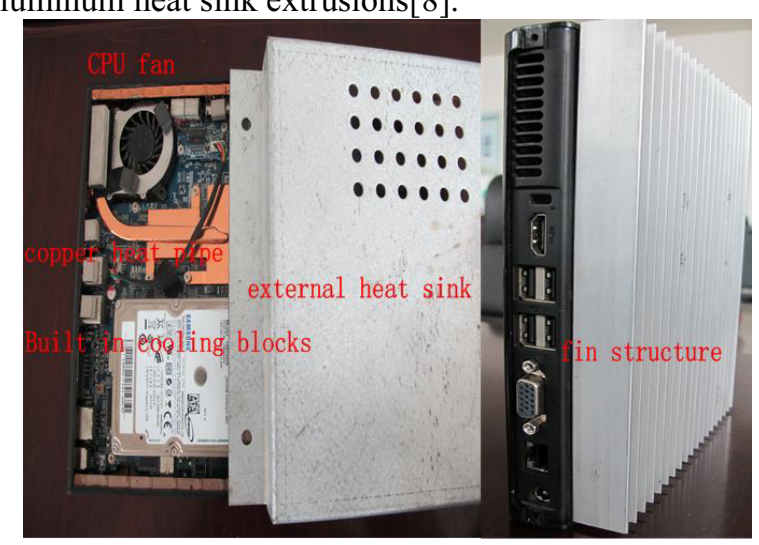

Figure 4. no fan for heat broadcast mechanism

The transformation is complete, Master Lu temperature monitoring software. Test conditions for fanless heat sink for broadcasting and broadcasting with fan cooling after the machine has been running for 30 days at the scene, together play a 8-minute video clip, then Master Lu measuring software testing[9].

Fan heat sink for broadcasting video playback after 5 minutes, CPU occupied $25 \%$, CPU temperature $82^{\circ} \mathrm{C}$, the hard disk temperature $43^{\circ} \mathrm{C}$, motherboard temperature of $46^{\circ} \mathrm{C}$ and CPU temperatures exceed $80^{\circ} \mathrm{C}$, Master $\mathrm{Lu}$ started the alarm, alarm message "CPU temperature is too high, check that the heatsink or fan is normal!"

Fanless heat sink for broadcasting is complete, CPU occupied $23 \%$, memory usage $39 \%$,CPU temperature $45{ }^{\circ} \mathrm{C}$, the hard disk temperature $41{ }^{\circ} \mathrm{C}$, motherboard temperature of $46{ }^{\circ} \mathrm{C}$. Master $\mathrm{Lu}$ revealed a normal temperature, heat sink in good condition.
Based power Group pilot municipal units of multimedia information publishing system, for example, describes Group multimedia information publish system design architecture and building. According to production requirements of practice and for multimedia information issuing system of broadcasting and control technology the machine cooling system. Next group corporate communications and information network will be based on the future requirements of the transition from IPv4 to IPv6, and to optimize the multimedia information publishing system upgrades.

\section{References}

1. Kampichler, W., Goeschka, K.M.: Plain End-to-End Measurement for Local Area Network Voice Transmission Feasibility. In: Proceedings 9th International Symposium on Modeling, Analysis and Simulation of Computer and Telecommunication Systems, pp. 235-240 (2001).

2. Q. Zheng and K.G. Shin, On the ability of establishing real-time channels in point-to-point packet-switched networks, IEEE Trans. Commun. 42(2/3/4) (1994) 1096-1105.

3. Wang, Q., Abu-Rgheff, M.A.: Integrated Mobile IP and SIP Approach for Advanced Location Management. In: 4th International Conference 3G Mobile Communication Technologies, pp. 205-209 (2003).

4. Sklar, B.: Digital Communications Fundamentals and Applications. Prentice-Hall International Editions (1988)

5. Mete Feridun and Stelios Karagiannis (2009) Growth Effects of Information and Communication Technologies: Empirical Evidence from the Enlarged EU, Transformations in Business and Economics, 8(2), 86-99.

6. Loeb, S.: Delivering Interactive Multimedia Documents Over Networks, IEEE Commun. Magazine 30 (1992) 52-59

7. Little T.D.C. and Ghafoor A.: Multimedia Synchronization Protocols for Broadband Integrated Services, IEEE J. on Sel. Areas in Commun. 9 (1991) 1368-1382

8. Bertsekas, D. and Gallager, R.: Data Networks, Prentice Hall (1992) 510-513

9. Norwicki,B.: NFS: Network File System Protocol Specification, RFC 1094.

\section{Summary}

